\title{
Promoción ambiental para la disminución de riesgos ambientales de la ciénaga de Concordia Magdalena ${ }^{1}$ \\ Environmental promotion for the reduction of environmental risks in the Concordia Magdalena swamp
}

DOI: http://dx.doi.org/10.17981/cultedusoc.9.2.2018.01

Fecha de recepción: 04/06/2018. Fecha de aceptación: 29/08/2018

\author{
Digna Flórez-Borja ${ }^{2}$ (iD \\ Martin Salas-De La Rosa ${ }^{3}$
}

Para citar este artículo

Flórez-Borja, D. y Salas-De La Rosa, M. (2018). Promoción ambiental para la disminución de riesgos ambientales de la ciénaga de Concordia Magdalena. Cultura. Educación y Sociedad 9(2), 9-20. DOI: http://dx.doi.org/10.17981/cultedusoc.9.2.2018.01

\section{Resumen}

El impacto ambiental en Colombia, consecuencia de la constante contaminación, especialmente en los ríos, se ha convertido en un foco atencional en el campo de la educación, razón por la cual se realizó el presente proyecto que tiene como objetivo identificar los riesgos ambientales de la Ciénaga de Concordia Magdalena. El estudio se llevó a cabo desde una mirada cualitativa, con un alcance descriptivo. Las técnicas de recolección de información fueron la entrevista estructurada y la observación. El escenario donde se llevó a cabo el estudio fué la Institución Educativa de Básica y Media de Concordia, Se contó con la participación de (40) estudiantes del grado décimo. Dentro de las conclusiones se puede decir que efectivamente es la ciénaga uno de los principales depósitos de desechos por parte de la comunidad Concordiana, razón que ha llevado a la afectación directa de ésta, logrando taponamientos y sequias.

Palabras clave: Promoción ambiental, riesgos ambientales, ciénaga.

\begin{abstract}
The environmental impact in Colombia, a consequence of constant contamination, especially in rivers, has become an attentional focus in the field of education, which is why the present project was carried out with the objective of identifying the environmental risks of the Ciénaga de Concordia Magdalena. The study was carried out from a qualitative perspective, with a descriptive scope. The information gathering techniques were the structured interview and the observation. The scenario where the study was carried out was the Basic and Media Educational Institution of Concordia, with the participation of (40) tenth grade students. Among the conclusions it can be said that the ciénaga is one of the main waste deposits on the part of the Concordia community, reason that has led to the direct affectation of this, achieving blockages and droughts.
\end{abstract}

Keywords: Environmental, promotion, environmental risks, swamp.

\footnotetext{
${ }^{1}$ Este artículo ha sido derivado del Programa de Fortalecimiento de la Cultura Ciudadana y Democrática CT+I a través de la IEP apoyada en TIC en el Departamento de Magdalena: CICLON.

${ }^{2}$ Líder del Grupo de investigación "PROMECOR”. Correspondencia: Email: dlfb.dlfb@gmail.com

${ }^{3}$ Docentes pertenecientes al grupo de investigación "PROMECOR” de la IED de Básica y media de Concordia, Sede Bto Nacionalizado de Concordia. Ciclón Magdalena, estrategia N² . Universidad de la Costa CUC.
}

- The author; licensee Universidad de la Costa - CUC. Cultura, Educación y Sociedad vol. 9 no. 2, pp. 9-20. Julio - Diciembre, 2018 Barranquilla. ISSN 2389-7724 Online 


\section{INTRODUCCIÓN}

La contaminación es un tema de gran interés en todo el mundo. En especial el manejo y uso del agua (ciénagas, ríos, etc.). Se constituyen como elemento primordial y vital para todo ser humano, y que requiere de gran atención por parte de los seres humanos. (Amérigo; García; y Sanchez. 2012). La ciénaga Cerro de San Antonio es la fuente más importante que tiene el municipio de Concordia de trabajo y alimentación pero en su deterioro se han dado diferentes problemáticas en los habitantes tales como el desempleo, destrucción del medio ambiente en general (flora y fauna), escases del recurso más importante el agua y contaminación ambiental en general.

En el municipio se vive un desastre ambiental a mediados del año 2015 hasta el presente, que fue la seguía de nuestra fuente hídrica la Ciénaga de cerro de San Antonio. Esta devastación se debió a una serie de factores o causas las cuales podemos describir de la siguiente manera; residuos sólidos en la ciénaga de Cerro de San Antonio y en las playas de la ciénaga, contaminación del cuerpo de agua, escases de agua, contaminación con herbicidas en cuerpos hídricos, falta de arborización, deforestación debido a la tala indiscriminada de árboles en las rondas de arroyos y quebradas, represamiento de arroyos, contaminación del aire, falta de confinamiento de animales, mal uso del suelo, uso indiscriminado de productos agroquímicos, alta sedimentación de la ciénaga, desequilibrio de la población y su medio ambiente, escases de alimentos, extinción de especies nativas (flora y fauna), pesca indiscriminada. (Amérigo M, y González A. 1996).
Por tal motivo surge el diseño de este proyecto de investigación que enmarca su propósito principal en identificar los riesgos ambientales qu e ocasionaron el deterioro de la Ciénaga de Concordia Magdalena. Actualmente las estrategias educativas buscan vincular el papel de la educación ambiental en las actividades al interior del aula, así mismo contribuir al enriquecimiento de los valores con el fin de generar una convivencia colectiva que propenda como fin último al cuidado de los recursos. Se hace entonces necesario potenciar capacidades y habilidades en los estudiantes para que puedan plantear desarrollar y atender a las problemáticas de orden medioambiental que contribuya al desarrollo sostenible de las sociedades. (Amérigo, Gonzales y Aragonés. 1995).

\section{Educación Ambiental}

La problemática ambiental ha hecho presencia de variadas formas, incluyendo factores de gran preocupación como lo es el calentamiento global, la destrucción de la capa de ozono, la tala de árboles y la contaminación de los ríos y el medio en general, acrecentando cada vez más las amenazas a las personas y a los resultados de su comportamiento. (Amérigo, Sevillano y cortés. 2005). Son las problemáticas evidenciadas a escala global y local las que tienen un punto característico y es básicamente el sistema económico al interior de un estado. (Herrera e Hinestroza, 2013) por tal razón es el tema medioambiental y sus constantes problemáticas que aumentan y esto tiene respuesta en los manejos discutibles en los gobiernos. Por tanto, la educación ambiental es un proceso que se debe desarrollar en 
todas las etapas de la vida y que tiene como objetivo lograr que las sociedades, (Niños, adolescentes, adultos), adquieran comportamientos proambientales, es decir conciencia ecológica, actitudes y valores que permiten accionar de manera responsable con el medio ambiente. (Amérigo y Gonzales, 1996).

Según el PNUMA (1987). "La educación ambiental debería en forma simultánea desarrollar una toma de conciencia, transmitir información, enseñar conocimiento, desarrollar hábitos y habilidades para promover valores, suministrar criterios y estándares y presentar pautas para la solución de problema y la toma de decisiones"

Educar ambientalmente implica el desarrollo de actitudes que permitan la comprensión de las relaciones entre los seres humanos, de acuerdo a las características de su cultura, por lo tanto, todo programa de educación ambiental deberá tener en cuenta la adquisición de conocimientos y el desarrollo de las habilidades. Así mismo se deberá promover la curiosidad, la toma de decisiones, estimulando acciones positivas.(PNUMA 1987, Corral 2000, Corral 2001).

\section{Riesgos ambientales}

Es entendible que el medio ambiente sufre diariamente distintos tipos de riesgos es el ser humano el único actor que propicia dichas situaciones. Ize \& Zuk (2010) Definen un riesgo como la probabilidad de que ocurra algo con consecuencias negativas. Los riesgos están presentes en la vida diaria de cualquier ser humano, y los hay de diversas magnitudes en todas las actividades realizadas.

El manejo del riesgo es un proceso que sirve como herramienta admi- nistrativa, para alcanzar una óptima gestión desde cualquier dimensión, en especial la institucional. El conocer sobre los riesgos debe hacer parte de una cultura institucional, pues si se detecta $\mathrm{y}$ gestiona el riesgo de forma eficaz y eficiente se puede ampliar las probabilidades de ampliar las metas y objetivos inicialmente propuestos. (Bertoni, M; López M. 2010).

Resulta entonces importante que una vez definido el riesgo, podemos especificar que desde el interés del investigador, se hace necesario hablar de riesgos medioambientales, no desconociendo que estos, son inherentes a cualquier actividad, ya sea en menor o mayor grado. Por lo tanto resulta un tema que abarca escenarios académicos, administrativos, incluyendo la rama directiva, los que buscan inicialmente trabajar en su identificación y evaluación. (SAA. s.f).

Un riesgo medio ambiental en el contexto educativo, se define como la probabilidad de ocurrencia de un fenómeno que afecta directa al entorno, convirtiéndose además en un peligro para la comunidad educativa, frente a este tipo de situaciones es importante trabajar mancomunadamente con los sujetos activos de la educación, para aplicar estrategias, que permitan disminuir el impacto ambiental, que pudiera ocasionar daños. (COEPA. s.f).

\section{Estudios de las ciénagas}

Las situaciones ambientales están reconocidas, como las llamadas humedales, que representan los ecosistemas dinámicos, cuyo componente fundamental es el agua, que fluye permanentemente en ambientes intermedios, que va desde las terrenos humedales y los terrenos secos, a este proceso se le 
determina diversidad biológica, por las características que presenta. Se considera que las características físicas, pueden ser moldeadas con métodos endógenos, como la sedimentación y la desecación y a técnicas exógenos, como inundaciones. (Tirado, Manjarrez \& Díaz. 2010).

El Ministerio del Medio Ambiente, Vivienda y Desarrollo Territorial, (2007). Define a las ciénagas dentro de los humedales y especifica que son ellas las que representan numerosos beneficios relacionados con funciones ecológicas y ambientales, debido a que sirven de soporte, para algunas actividades productivas y socio-culturales que mantienen la biodiversidad, pero que necesitan de un sistema humedal permeante, una de las técnicas para los humedales son el sistema de control de los humedales, para fortalecer el sistema de riego. Pero los humedales deben ser tratados con técnicas especiales para evitar desastres ambientales. (Corral, V. 2010).

Las ciénagas son humedales de importancia ambiental por sus peculiaridades. Por tanto se convierten técnicas innovadoras para los cultivos y su productividad. Sin embargo estos humedales, deben ser controlados de tal manera; para evitar grandes inundaciones, estanque de grandes cantidades de agua, regulación de caudales de los ríos, retener los sedimentos al maximizar procesos de decantación y depósitos de materiales purificando el agua proveniente de las cuencas y de los asentamientos humanos adyacentes. Estos sistemas de control de los humedales, se convierten en el hábitat de reserva, para una rica biodiversidad de flora y fauna, que viene a representar la biodiversidad natural de poblaciones y regiones aledaña a la población Colombiana. De esta manera se protegen las reservas de las Ciénegas en el país y la región, siempre y cuando se le den tratamientos de conservación de esta riqueza natural. (Morelo \&Fonseca s.f).

Para algunas personas del contexto y de la región del Magdalena, consideran que las ciénagas son terrenos anegados, fangosos e inútiles, susceptibles únicamente, de desecación para fines agropecuarios y ganaderos. Sin embargo para otra parte de la población, se resaltan los cuidados y tratamientos que le dan a la misma; siendo los productos naturales que se cultivan a su alrededor, los que facilitan al campesino y al agricultor un satus de vida mejor. Porque estas personas le dan la utilidad necesaria a la ciénega para su propio beneficio y sustento diario. El proceso que se le da a las ciénagas, permiten ver un alto potencial productivo y su ingerencia socioeconómica como parte de del campesino y el agricultor. Por tanto esta reserva natural amerita sus cuidados y técnicas para su conservación y que más que las instituciones educativas, organicen planes estratégicos, para la preservación de la natural. (Corral, V, y Pinheiro J.2004).la actuación de las ciénagas, deja ver dos caminos uno el periodo de aguas bajas que es la siembra de cultivos transitorios y el periodo dos, que corresponde al de aguas alta, considerada como el aprovechamiento del recurso pesquero; convirtiéndose para las pesqueros o pescadores, como una manera de subsistir por la economía de la estructura pesquera, considerada únicamente en este periodo. (Morelo \& Fonseca s.f).

Colombia, cuenta con alrededor de 20 millones de hectáreas de humedales, entre los que se encuentran las ciénagas. 
En la costa Caribe colombiana, se registra la mayor variación de humedales referenciados como: ribereños, lacustres, palustres, marinos y estuarinos. Estas zonas ribereñas son reconocidas por sus amplias playas arenosas y fondos lodosos, que viene a formar parte de los ecosistemas. En este sentido se le reconoce a la Ciénaga Grande del Magdalena, como la Ciénega donde desembocan los ríos Sinú y Atrato, la bahía de Cartagena y la Ciénaga de las Quintas, esta ciénaga se destaca por su afluencia con los ríos del resto del país.. (Tirado, Manjarrez \& Díaz. 2010).

Los esfuerzos actuales se han centrado en poder hacer evaluación de la pesca, principalmente en el rio Magdalena y sus ciénagas conspicuas. Es aquí donde se observa numerosas alteraciones en los sistemas naturales de conexión entre ciénagas y sus afluentes. Lo más comunes son lo taponamientos o ensanches de caños y canales sin un análisis previo de su importancia y su relación con el resto del ecosistema, así como también la obstrucción de los caños naturales. (Corral, V, García F., Tapia C y Fraijo B 2012).

\section{Contaminación de la ciénaga de cerro de San Antonio}

De acuerdo con el International Water Management Institute de Sri Lanka, aproximadamente un cuarto de la población mundial vive ahora en áreas donde hay escasez de agua, en las cuales el agua está siendo usada para fines industriales, agrícolas y domésticos, de manera más rápida de lo que permite el ciclo del agua. Adicionalmente, cerca de mil millones de personas enfrentan escasez de agua debido a que sus gobiernos carecen de los recursos o de la capacidad para desarrollar reservas de agua potable. La escasez de agua afecta principalmente a las personas pobres. Las personas pobres con frecuencia carecen de acceso a agua potable para beber, lo cual causa perjuicios a su salud o pérdida de tiempo productivo al tener que caminar largas distancias para encontrar agua segura.

La Ciénaga de Cerro de San Antonio, que comparten los municipios de Concordia y Cerro de San Antonio, es otro cuerpo de agua que afronta una crisis ambiental en el Magdalena. El alcalde de Concordia, Pedro Ospino, dijo que esta ciénaga está diezmada en un 80 por ciento y no tienen de donde captar el agua para el consumo humano, por lo que debe traerla de municipios vecinos como Cerro de San Antonio, Pedraza y El Piñón, lo cual tiene al Municipio al borde del colapso financiero.

Hoy se tiene un caño que está taponado en su desembocadura en la ciénaga por efecto de la sedimentación. El caño perdió velocidad de arrastre, la lámina de agua no podía arrastrar las partículas en suspensión, nos creó un delta y ese delta hoy está funcionando como un tapón que represa el agua que el río está metiendo a la Ciénaga de Cerro de San Antonio. La ciénaga ha sufrido no solo el taponamiento, y la sequía, sino además la contaminación a las aguas es origen de la presencia constantes de basuras que los habitantes arrojan diariamente, motivo por el cual desde años atrás ha generado un dragado generando un impacto medioambiental o dicho de otra manera desastres ecológicos. En palabras del Alcalde del Municipio de Concordia Pedro Ospino en el año 2016 "una crisis humanitaria sin precedentes", debido a la falta de consciencia de los habitantes, y de los pocos recursos para mitigar esta problemática. 
El comité de prevención y desastres en Concordia (2017) dice que, una de los mayores afluentes de enfermedades infectocontagiosas es a raíz de las basuras que son desechados en la ciénaga, producto de ellos se generan bacterias, zancudos, que traen consigo efectos secundarios para la salud sobre todo de las personas que viven aledañas a ella.Se necesita una canalización del caño, un dragado de la ciénaga, una reforestación de toda esta zona y un repoblamiento con más de un millón de alevinos y declarar esta zona patrimonio para que descanse porque las malas prácticas han contribuido a que todo este ecosistema poco a poco vaya desapareciendo. Así mismo se requiere de una población empoderada por las necesidades medioambientales, educada culturalmente, y que sea autónoma en la protección del medio ambiente, y en especial de la ciénaga como medio de subsistencia.

Es la ciénaga de san Antonio la que se constituye como fuente principal de ingreso para los habitantes del Municipio de cerro de san Antonio y Concordia Magdalena, incluyendo sus corregimientos. Es la fuente básica de consumo vital, a través de ella se permite la generación de ingresos a través de la pesca, el transporte marítimo, también favorece a la economía, la agricultura y ganadería soportan el ingreso de dinero en los hogares. (Plan de Desarrollo Ambiental de Concordia. 2016).

\section{Metodología}

Este estudio se llevó a cabo desde una mirada Cualitativa, pues la intención es interpretar y comprender la realidad de los fenómenos estudiados. (Martinez, 2006). El alcance es descriptivo y un diseño de campo.

\section{Escenarios y actores}

La investigación fue llevada a cabo en la Institución Educativa de Básica y Media de Concordia, Departamento del Magdalena. Los participantes fueron los (40) estudiantes de décimo grado. 20 del grupo A y 20 del grupo C.

\section{Técnicas e instrumentos de recolección de la información}

Dado el tipo de investigación cualitativa y las características del escenario de investigación se decide utilizar como técnicas de recolección: la entrevista estructurada, permitiendo que la información sea registrada para su categorización e interpretación. De igual manera se empleó la observación participante, y la información fue registrada en un diario de campo.

\section{Procedimiento}

Momento (1): Se seleccionan los instrumentos a utilizar.

Momento (2): Se especifican las categorías de estudio.

Momento (3): Se escoge los instrumentos de recolección de información.

Momento (4): Con base a las categorías de estudio: Riesgos ambientales, promoción ambiental; se aplicó a los participantes la entrevista, la cual pretende describir el fenómeno que se estudia partiendo del nivel de la investigación (no experimental) en donde se observa, y analiza tal y como acontece.

Momento (5): Una vez se tiene los resultados de la entrevista estructurada y la observación registrada se interpretan y comprenden los resultados a la luz de lo que exponen los teóricos que soportan la investigación.

Momento (6): Se relacionan los resultados y se muestran los hallazgos. 


\section{Resultados}

\begin{tabular}{|c|c|c|c|}
\hline $\begin{array}{c}\text { Categoría de } \\
\text { estudio }\end{array}$ & $\begin{array}{c}\text { Pregunta } \\
\text { orientadora }\end{array}$ & Discurso de los actores & Articulación y sistematización teórica \\
\hline $\begin{array}{l}\text { Riesgos } \\
\text { ambientales }\end{array}$ & $\begin{array}{l}\text { ¿Por qué } \\
\text { cree usted } \\
\text { que los } \\
\text { habitantes } \\
\text { han } \\
\text { escogido } \\
\text { las ciénagas } \\
\text { para arrojar } \\
\text { basura? }\end{array}$ & 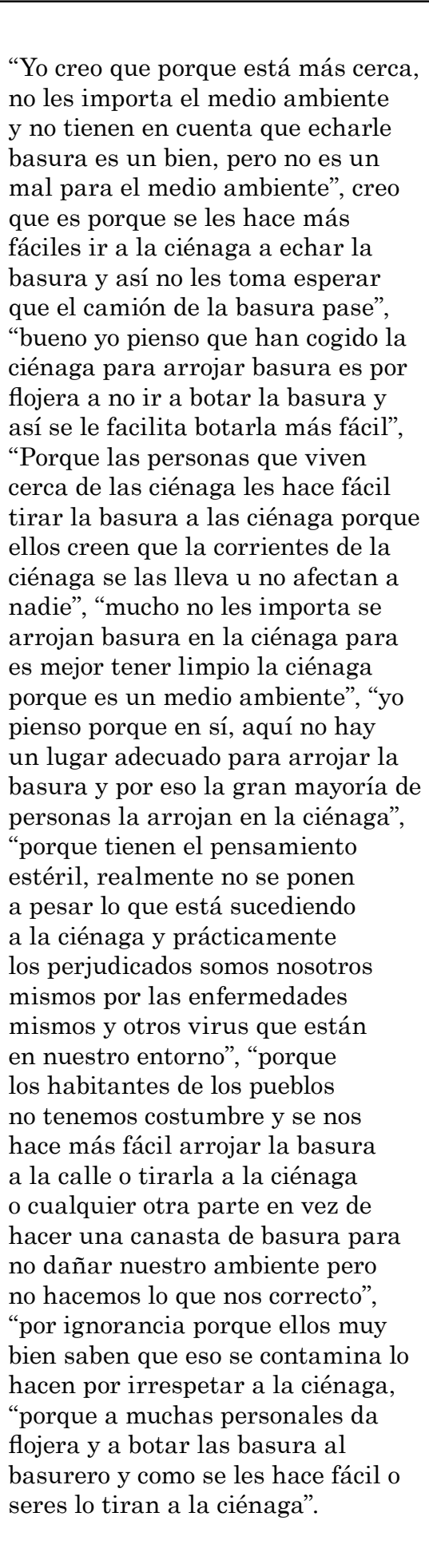 & 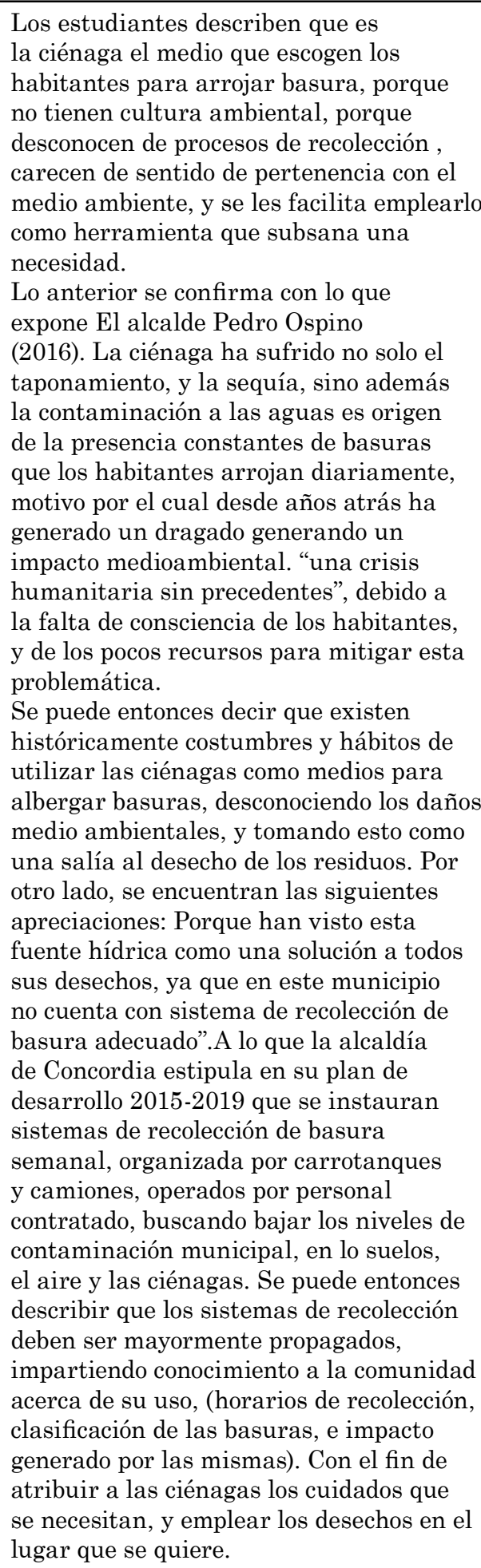 \\
\hline
\end{tabular}


¿Considera usted que las ciénagas

Riesgos ambientales

son un

elemento importante de impacto medio ambiental?
"Si claro por qué la ciénaga son recursos, la ciénaga nos dan alimento, etc.", "si porque la ciénaga es un recurso que todos necesitamos", "yo considero que las ciénagas son vitales porque ellas nos sostienen y de ellas consumismos peces y nos beneficiamos mucho de ellos", "pues si claro yo pienso es que un elemento muy importante la debemos cuidar mucho", "si porque sin la ciénaga no habría peces y los pescadores no tendrían donde pescar", es un elemento más importante para nosotros la necesitamos para mucho trabajos por mas ese nuestro al ambiente lo utilizaron", "el agua es el elemento más importante para poder subsistir y también muchas personas viven de la pesca a la otras les sirve como medio de trasporte lugares", "si claro, como aquí en la comunidad la ciénaga es muy importante es como si fuera nuestra madre porque de ella estamos todos en la vida la utilizamos para muchas cosas que al fin terminamos contaminándola con nuestras acciones en la vida cotidiana”, claro porque ahí habitan los animales que son necesarios para nuestra alimentación como lo es el pescado además la ciénaga es un elemento importante para nosotros los que vivimos a su alrededor porque es un recurso necesario para todos"
Todos los estudiantes coinciden que la ciénaga si se constituye como elemento primordial y de impacto medio ambiental, pues es una fortuna contar con aguas que originan y favorecen desarrollo económico y calidad de vida. Lo anterior, es coherente con lo que expone el Plan de Desarrollo Ambiental de Concordia. (2016). Quien afirma que es la ciénaga de san Antonio la que se constituye como fuente principal de ingreso para los habitantes del Municipio de cerro de san Antonio y Concordia Magdalena, incluyendo sus corregimientos. Es la fuente básica de consumo vital, a través de ella se permite la generación de ingresos a través de la pesca, el transporte marítimo, también favorece a la economía, la agricultura y ganadería soportan el ingreso de dinero en los hogares.

Dos estudiantes por su parte, toman en cuenta los siguientes aspectos: "si claro por qué la ciénaga es un ecosistema donde se encuentran muchos animales y ayuda recolectando agua que las habitan", "claro porque esta alberga una gran variedad de ecosistemas acuáticos". Se sustenta lo anterior, cuando se reconoce que efectivamente las ciénagas son humedales de importancia ambiental, teniendo en cuenta las características de controlar las inundaciones, evitar el estancamiento de grandes cantidades de agua, regular los caudales de los ríos, retener los sedimentos, maximizar los procesos de decantación y depósitos de materiales purificando, proveniente de las cuencas y de los asentamientos humanos adyacentes. Estos sistemas de humedales le aportan al sistema de hábitat para una rica biodiversidad cultural de flora y de fauna, aportándoles valor económico a los campesinos y agricultores, porque es una forma subsistir a su medio de vida. (Morelo \&Fonseca s.f). 


$\begin{array}{ll} & \text { ¿Qué cree } \\ & \text { usted que } \\ \text { Promoción } & \text { pasa cuando } \\ \text { ambiental } & \text { se arroja }\end{array}$

basura a las ciénagas?
Promoción ambiental

\begin{abstract}
"Creo que se contamina, también mata a los peces, y las personas que requieren de este recurso se podrían enfermar", "yo creo que cuando arrojamos basura a las ciénagas, la ciénaga genera mal olor y mal aspecto y todos los peces mueren etc.”, "pues yo pienso que estamos dañando el medio ambiente cuando se arroja basura a la ciénaga se puede bañar si la siguen utilizando como basurero", la contaminamos primero que todo los perjudicados somos nosotros mismos y los culpables también, también se pierde una fuente hídrica los peces se mueren y después no tenemos con que sostenernos",

"Se contamina así lo que uno logra es ganar una enfermedad ya que el agua es muy importante para nuestra vida ya que no la sabemos aprovechar"
\end{abstract}

Dar charla orientar a las personas que la policía este pendiente etc.", "yo llevaría a cabo que las personas que arrojan basura sea sancionado para que nadie más arroje basura", "lo primero es decirle a las personas que no sigan arrojando basura que por medio de eso podremos seguir y la hora es no estar dañando la ciénaga por estar echando basura y no permitir que la dañen", "yo pienso que deberían poner letreros que digan no arrojar basura y si ven a alguien arrojarla basura ponerme una multa”, poner un aviso que diga peligro arrojar basura si contaminas el medio ambiente contaminan tu vida.
Todos los participantes coincidieron que los resultados que se generan tras botar basura a la ciénaga es en primera instancia la contaminación, seguido del perjuicio para los seres humanos, y finalmente se ocasiona muerte a los animales que allí existen. En sintonía que los hallazgos encontrados se puede afirmar que la ciénaga ha sufrido no solo el taponamiento, y la sequía, sino además la contaminación a las aguas es origen de la presencia constantes de basuras que los habitantes arrojan diariamente, motivo por el cual desde años atrás ha generado un dragado generando un impacto medio ambiental o dicho de otra manera desastres ecológicos. En palabras del alcalde Pedro Ospino (2016). "una crisis humanitaria sin precedentes", debido a la falta de consciencia de los habitantes, y de los pocos recursos para mitigar esta problemática.

El comité de prevención y desastres en Concordia (2017) afirma que, una de los mayores afluentes de enfermedades infectocontagiosas es a raíz de las basuras que son desechados en la ciénaga, producto de ellos se generan bacterias, zancudos, que traen consigo efectos secundarios para la salud sobre todo de las personas que viven aledañas a ella.

Las consecuencias que trae arrojar basura a la ciénaga, seguido de que se deben colocar avisos que permitan general cultura ambiental, y así mismo instaurar castigos para erradicar las acciones contaminantes frente a la ciénaga.

Lo anterior deja claro, cuando se tiene en cuenta sustenta, lo planteado por el Ministerio del Medio Ambiente y el Ministerio de Educación Nacional cuyo propósito fundamental es desarrollar un marco conceptual y metodológico, con el fin de tener claridad conceptual, para desarrollar programas y proyectos educativos articulados al (PEI). Proyecto educativo institucional, de manera transversal para darle respuesta a una sentida necesidad, como es el medio ambiente. Destacando la participación de la educación en propuestas ambientales, con miras a responder a las desafíos de los problemas naturales. Se busca de esta manera consolidar proyectos para fortalecer la cultura ambiental ética y responsable en un al línea de manejo sostenible.

Fuente: Elaboración propia. (2018). 


\section{Conclusiones}

A la luz de los resultados se toman en consideración las siguientes conclusiones:

a. Los estudiantes reconocen que se debe Sensibilizar a la población acerca del cuidado medioambiental, sobre todo al manejo de basuras que terminan perjudicando directamente a la ciénaga de cerro de san Antonio. Asocian los factores de contaminación a la apatía por la ecología, a la carencia de medios de recolección, $\mathrm{y}$ al desconocimiento de formas para proteger el entorno.

b. Identifican cuales fueron los factores que ocasionaron no solo la sequía de la sequía sino además la mortandad de animales propios de las aguas magdalenenses, sin embargo atribuyen la anomalía a la poca atención por los entes gubernamentales.

c. Destacan que el municipio de Concordia desde hace años viene sobrellevando diversos riesgos ambientales, y que el mayor riesgo ha sido el presentado en los últimos tres años, no solo por la contaminación, sino por la escases de medios alimenticios originados por la pesca, la obtención de empleo a través del transporte marítimo, y sobre todo por la carencia de agua para las necesidades básicas.

d. Hacen énfasis en que la escuela genere programas para los estudiantes de todas las edades sobre el cuidado medioambiental, que se reconozcan los factores protectores y de riesgos del entorno. Logran identificar que la participación y puesta en marcha de estrategias para generar cultura ambiental debe contar con la articulación de la escuela, la familia y los entes gubernamentales, pues en concordancia con estos tres entes se puede no solo sensibilizar, sino minimizar y transformar los problemas en oportunidades de desarrollo y crecimiento.

e. Se motivan a participar en actividades de reciclaje, salidas de campo, reconocimiento de las zonas contaminadas, diseño de propuestas de solución para las mismas, jordanas de aseo, campañas de salud entre otros.

\section{Referencias}

Alcaldía de Envigado. (2011). Guía para el adecuado manejo de los residuos sólidos y peligrosos. Documento recuperado de: http://www.ambientalex.info/ guias/Guia_manejo_residuos_sp.pdf

Amérigo M, y González A. (1996). Preocupación medioambiental en la población escolar. Revista de Psicología Social Aplicada, 6(1), 75-92.

Amérigo M., García, J. y Sanchez Trinidad (2012). Actitudes y comportamiento hacia el medio ambiente natural. Salud medioambiental y bienestar emocional. Universitas Psychologica. 12(3). 845-856.

Amérigo María, González A y Aragonés J. (1995). Antropocentrismo versus etnocentrismo en una muestra de estudiantes. Psicología política, jurídica $y$ ambiental. 2. 337-344.

Aragonés J., Amérigo M., Sevillano V., y Cortés B. (2005). La estructura de las creencias sobre la problemñatica medioambiental. Psicothema, 17(2). 257-262.

Arroyo P. (2012). Diseño de programas de reciclaje de e-waste considerando las motivaciones del participante: Un estudio exploratorio en el estado de México. Psyechology: Revista bilingüe de psicología ambiental, 3(1). pp. 3-14. 
Avendaño, I., Cortés, O., Guerrero, H. (2015) Competencias sociales y tecnologías de la información y la comunicación como factores asociados al desempeño en estudiantes de básica primaria con experiencia de desplazamiento forzado Diversitas: Perspectivas en Psicología, vol. 11, núm. 1, 2015, pp. 13-36 Universidad Santo Tomás Bogotá, Colombia.http://www.scielo.org.co/pdf/dpp/ v11n1/v11n1a02.pdf.

Barón, R. y Byrme, D. (2005). Psiología Social. México: Pearson

Berenguer, J. (1998). Actitudes y creencias ambientales. Una explicación psicosocial del comportamiento ecológico. Tesis doctoral, Universidad Autónoma de Madrid.

Bertoni, M. y López M. (2010). Percepciones sociales ambientales Valores y actitudes hacia la conservación de la Reserva de Biosfera "Parque Atlántico Mar Chiquita”-Argentina. Estudios y perspectivas en turismo. 19(5). pp. 103-115.

Boada, A. (2003). El reciclaje, una herramienta no un concepto reflexiones hacia la sostenibilidad. Universidad Externado de Colombia. Documento recuperado de: http://www.ingenieroambiental.com/4014/reciclaje5.pdf CEPIS. (2001). Marco conceptual de los residuos sólidos. Documento recuperado de: http://www.bvsde.paho.org/ bvsars/e/fulltext/marco/marco.pdf

CONAM. (s.f). Guía para la implementación del programa piloto de reaprovechamiento de residuos sólidos en huamanga, Pucallpa y Tingo María. Documento recuperado de: http:// www.bvsde.paho.org/bvsacd/cd27/ guia-reapro.pdf
Contreras, C. (2006). Manejo integral de aspectos manejo integral de aspectos ambientales-residuos sólidos. Pontificia Universidad Javeriana. Bogotá D.C. Colombia. Documento recuperado de: http://www.javeriana.edu.co/ ier/recursos_user/IER/documentos/ OTROS/Pres_Residuos_CamiloC.pdf

Corral, J., y Berenguer, J. (1998). Estructura de las actitudes ambientales: ¿Orientación general o especialización actitudinal? Revista de Psicología Social, 13(3), 399-406

Corral, V, García F., Tapia C y Fraijo B (2012). Sustainable behaviors and perceived psychological restoration. Revista Acta de investigación psicológica, 2(2), 749-764.

Corral, V, y Pinheiro J. (2004). Aproximaciones al estudio de la conducta sustentable. Medio Ambiente y Comportamiento Humano, 5(1y2). 1-26.

Corral, V. (2000). La definición del Comportamiento proambiental. La psicología social en México, Vol. 8, pp. 466-467.

Corral, V. (2001). Comportamiento proambiental. Santa Cruz de Tenerife: Editorial Resma.

Corral, V. (2010). Psicología de la sustentabilidad. Un análisis de lo que nos hace pro ecológicos y pro sociales. México: Trillas.

González. C. (2007). Reciclaje: para la protección del ambiente y los recursos naturales. Documento recuperado de: http://www.uprm.edu/taubetapi/ library/docs/Presentacion\%20Charla\%20de\%20Reciclaje.pdf

Jaramillo, J. (1997). Guía para el diseño, construcción y operación de rellenos sanitarios manuales. Documento recuperado de: http://bibliotecavirtual. minam.gob.pe/biam/bitstream/id/606/ BIV00155.pdf 
Herrera-Tapias, B, y Hinestroza, L. (2013). Los procesos de Desarrollo en Colombia: Una reflexión desde la Políticas del Banco Mundial y las Instituciones. Revista advocatus edicion especial 21,(1). 51-70.

Ley de Residuos Sólidos. (s.f). Cómo y porqué separar las basuras. Documento recuperado de: http://www.bvsde. paho.org/bvsacd/cd48/juntos.pdf

Marmolejo, L., Torres, P., Oviedo, E., Bedoya, E., Amezquita, C., Klinger, R., Albán, F., \& Díaz, L. (2009). Flujo de residuos: Elemento base para la sostenibilidad del aprovechamiento de residuos sólidos municipales. Ingeniería y competitividad. 1(2). Universidad del Valle. Colombia.

Norma Técnica Colombiana GTC. (2009). Gestión Ambiental. Residuos Sólidos. Guía para la separación en la fuente. Documento recuperado de: http://www.bogotaturismo.gov.co/ sites/intranet.bogotaturismo.gov.co/ files/GTC\%2024\%20DE\%202009.pdf

Novo, M. (2009). La educación ambiental, una genuina educación para el desarrollo sostenible. Revista de Educación. Documento recuperado de: http://www.revistaeducacion.mec.es/ re2009/re2009_09.pdf

PNUMA. (1990). Educación ambiental: modulo para la formación de profesores de ciencias y de supervisores para escuelas secundarias. Orelac. Santiago de Chile. Documento recuperado de: http://unesdoc.unesco.org/ images/0007/000714/071480so.pdf
Roben, E. (2003). El Reciclaje. Oportunidades Para Reducir la Generación de los Desechos Sólidos y Reintegrar Materiales Recuperables en el Círculo Económico. DED, 2(22).

Sandoval. C. (2002). Investigación cualitativa. ARFO. Bogotá Colombia. Documento recuperado de: https:// panel.inkuba.com/sites/2/archivos/ manual\%20colombia\%20cualitativo. pdf

Sauvé, L. (1999). La educación ambiental entre la modernidad y la posmodernidad: En busca de un marco educativo de referencia integrador. Tópicos, 1 (2). Documento digital recuperado de: http://www.ecominga.uqam.ca/PDF/ BIBLIOGRAPHIE/GUIDE_LECTURE_1/5/2.Sauve.pdf

Secretaría de Medio Ambiente y recursos naturales. (s.f). Residuos sólidos urbanos: La otra cara de la basura. Documento recuperado de: https:// www.gob. $\mathrm{mx} / \mathrm{cms} /$ uploads/attachment/file/39412/RESIDUOS_SOLIDOS_URBANOS-_ENCARTE.pdf

UNICEF. (s.f). Experiencias urbanas de gestión integral de residuos en 10 municipios de Argentina. Documento recuperado de: https://www.unicef. org/argentina/spanish/EcoclubesbajaWEB.pdf

Universidad Nacional de Mar de la plata. (2016). Facultad de Ciencias Económicas y sociales. Documento recuperado de: https://eco.mdp.edu. ar/institucional/eco-enlaces/1611-labasura-consecuencias-ambientalesy-desafios. 